\title{
Lipid Rafts Mediate Amyloid-Induced Calcium Dyshomeostasis and Oxidative Stress in Alzheimer's Disease
}

\author{
Elisa Evangelisti ${ }^{\mathrm{a}}$, Daniel Wright ${ }^{\mathrm{a}}$, Mariagioia Zampagni ${ }^{\mathrm{a}}$, Roberta Cascella ${ }^{\mathrm{a}}$, Claudia Fiorillo $^{\mathrm{a}}$, \\ Silvia Bagnoli ${ }^{\mathrm{b}}$, Annalisa Relini ${ }^{\mathrm{c}}$, Daniela Nichino ${ }^{\mathrm{c}}$, Tania Scartabelli ${ }^{\mathrm{d}}$, Benedetta Nacmias ${ }^{\mathrm{b}}$, \\ Sandro Sorbi ${ }^{\mathrm{b}}$ and Cristina Cecchi ${ }^{\mathrm{*}}$
}

${ }^{a}$ Department of Biochemical Sciences, ${ }^{b}$ Department of Neurological and Psychiatric Sciences, University of Florence, 50134, Florence, ${ }^{c}$ Department of Physics, University of Genoa, 16146, Genoa, ${ }^{d}$ Department of Preclinical and Clinical Pharmacology, University of Florence, 50134, Florence, Italy

\begin{abstract}
Several lines of evidence suggest that the initial events of amyloid- $\beta$ peptide (A $\beta$ ) oligomerization and deposition in Alzheimer's disease (AD) involve the interaction of soluble oligomers with neuronal membranes. In this study, we show that $\mathrm{A} \beta 42$ oligomers are recruited to lipid rafts, which are ordered membrane microdomains rich in cholesterol and gangliosides, resulting in lipid peroxidation, $\mathrm{Ca}^{2+}$ dyshomeostasis and membrane permeabilization in primary fibroblasts from familial AD patients (FAD) bearing APPVal717Ile, PS-1Leu392Val or PS-1Met146Leu gene mutations. Moreover, the presence of significantly higher levels of lipid peroxidation correlated with greater structural modification in detergent resistant domains (DRMs) isolated from APP and PS-1 fibroblasts, compared to WT fibroblasts from healthy subjects. Modulation of raft GM1, including modest depletion of GM1 content and interference with GM1 exposure or negative charge, precluded the interaction of amyloid aggregates with the plasma membrane and the resulting cell damage in FAD fibroblasts and rat brains cortical neurons. These findings suggest a specific role for raft domains as primary mediators of amyloid toxicity in $\mathrm{AD}$ neurons.
\end{abstract}

Keywords Alzheimer's disease fibroblasts, amyloid aggregate toxicity, calcium dysregulation, membrane GM1, oxidative stress, primary cortical neurons.

\section{INTRODUCTION}

Alzheimer's disease (AD) is a common form of dementia that results in memory loss and impairment of cognitive function in the elderly. A major pathological hallmark of AD is the formation of extracellular senile plaques composed of aggregated amyloid $\beta$-peptide (AB) [1]. $A \beta$ is generated by sequential enzymatic cleavage of the amyloid precursor protein (APP) by $\beta$-secretase and the $\gamma$-secretase complex, which displays presenilin activity [2-4]. Although the majority of $\mathrm{AD}$ cases $(>90 \%)$ occur after the age of 60 , a small proportion $(5 \%)$ of cases correspond to early-onset $(<60$ years) familial AD (FAD). Autosomal-dominant forms of FAD result from specific mutations in one of three genes: APP on chromosome 21, presenilin 1 (PS-1) on chromosome 14 or presenilin 2 (PS-2) on chromosome 1 [5]. Mutations in these three genes appear to trigger very similar pathological mechanisms, which ultimately accelerate $A \beta$ aggregation, deposition and neurotoxicity [6].

Several lines of evidence suggest that soluble oligomers may be the principal neurotoxic agent $[7,8]$ in $\mathrm{AD}$. Indeed, amyloid-derived diffusible ligands (ADDLs) are found in the cerebrospinal fluid of AD patients [9]. Moreover, ADDL

*Address correspondence to this author at the Department of Biochemical Sciences, University of Florence, Viale Morgagni 50, 50134 Florence, Italy; Tel: +39 (055) 4598320; Fax: +39 (055) 4598905;

E-mail: cristina.cecchi@unifi.it levels in human brains better correlate with disease severity than do classical amyloid plaques containing insoluble $A \beta$ deposits [10], while fibril-free oligomers have been shown to be toxic to cultured cells and neurons [11].

A 342 oligomer toxicity appears to result from their intrinsic ability to impair fundamental cellular processes via interaction with cellular membranes, triggering oxidative stress and an increase intracellular free $\mathrm{Ca}^{2+}$ that eventually leads to apoptotic or necrotic cell death [12-16].

Cell membrane structure is based on the dynamic clustering of sphingolipids and cholesterol, which form lipid rafts also known as detergent-resistant membrane fractions (DRMs) - that float freely through the more fluid lipid bilayer [17]. These structures are selectively enriched in specific classes of proteins and lipids, and are thus thought to play specialized roles in signal transduction, cell-cell recognition processes and vesicular trafficking [18]. Increasing evidence suggests that $A \beta$ can associate with lipid rafts and components of DRMs isolated from human and rodent brains, as well as from cultured cells [19-21]. In addition, recent data suggests a specific role for lipid rafts in mediating $A \beta$-induced oxidative attack on plasma membranes and subsequent alteration of cell surface properties [19, 22]. A $\beta$ has been found to be tightly associated with monosialoganglioside GM1, and it was originally postulated that this interaction might act as a seed for $A \beta$ accumulation and aggregation [23-26]. In particular it has been shown that GM1 clus- 
ters, promoted by alteration of membrane lipid composition, are critical for the formation of GM1-A $\beta$ complexes [27]. However, no clear mechanistic evidence regarding the relationship between lipid raft content and amyloid toxicity is currently available.

In this study, we investigated the specific ability of lipid rafts to bind soluble $\mathrm{A} \beta 42$ oligomers and the resulting changes in membrane structure in rat brain cortical neurons and cultured skin fibroblasts from FAD patients bearing APPVa17171le, PS-1Leu392Val or PS-1Met146Leu gene mutations, compared to age-matched healthy subjects. We found that lipid rafts/DRMs are primary targets of $A \beta$ induced physicochemical perturbation at the cell surface, which triggers increased lipid peroxidation and cytosolic calcium dyshomeostasis, ultimately resulting in cell death.

\section{MATERIALS AND METHODS}

\section{Cell Cultures and Treatment}

Nine fibroblast lines were obtained from punch biopsies of the upper arm, which were taken from three Italian patients bearing the APPVal717Ile mutation, three Italian patients bearing PS-1Leu392Val or PS-1Met146Leu mutations, and three age-matched healthy subjects. Patient clinical assessments were carried out according to published guidelines, and the $\mathrm{AD}$ diagnosis fulfilled the Diagnostic and Statistical Manual of Mental Disorders criteria (DSM-IV) [28, 29]. The local ethical committee approved the protocol and written consent was obtained from all subjects or, where appropriate, their carers. Fibroblasts were cultured in Dulbecco's Modified Eagle's Medium (DMEM, Sigma, Milan, Italy) supplemented with $10 \%$ fetal bovine serum (FBS, Sigma), $1 \%$ glutamine (Sigma), and a solution of $1 \%$ penicillin and streptomycin (Sigma), and subjected to an equal number of passages (ranging from 15 to 20). The release of endogenous $A \beta 42$ into cell culture media was quantified using an A $\beta 42$ ELISA kit (Molecular Probes, Eugene, OR, USA). Fibroblasts were exposed to $1.0 \mu \mathrm{M} A \beta 42$ oligomers (Sigma), obtained according to Lambert's protocol, and morphologically characterized by AFM analysis as previously reported [19].

Primary cortical neurons were obtained from embryonic day (ED)-17 Sprague-Dawley rats (Harlan, Italy). Experimental procedures were in accordance with the standards set forth in the Guide for the Care and Use of laboratory Animals (published by the National Academy of Science, National Academy Press, Washington, D.C.). Uteri were removed from the gravid rat under anesthesia. Cerebral cortices were dissociated in sterile Dulbecco's phosphatebuffered saline (D-PBS; Sigma), and neurons isolated in the same medium containing trypsin $(0.5 \%$ in sterile D-PBS) for $10 \mathrm{~min}$ at $37^{\circ} \mathrm{C}$. After centrifugation, dissociated neurons were re-suspended in neurobasal medium (NBM; Gibco, Invitrogen Corporation, Milan, Italy) supplemented with $2 \%$ B-27 (Gibco) and $0.5 \mathrm{mmol} / \mathrm{L}$ glutamine (Gibco), and then seeded in poly-L-lysine-coated 24-well plates at a density of approximately $4.5 \times 10^{4}$ cells/well. Cultures were maintained in $\mathrm{NBM}$ at $37^{\circ} \mathrm{C}$ in a $5 \% \mathrm{CO}_{2}$-humidified atmosphere. Neurons were exposed to $5.0 \mu \mathrm{M} \mathrm{A} \beta 42$ oligomers 14 days after seeding.

\section{DRM Purification and Structural Analysis}

Fibroblasts were dispersed in a $10 \mathrm{mM}$ Tris- $\mathrm{HCl}$ buffer, $\mathrm{pH} 7.5$, containing $150 \mathrm{mM} \mathrm{NaCl}, 5.0 \mathrm{mM}$ EDTA, $1.0 \mathrm{mM}$ $\mathrm{Na}_{3} \mathrm{VO}_{4}$ and $1 \%$ Triton $\mathrm{X}-100$ (TNE buffer) with protease inhibitors, disrupted using a Dounce homogenizer and centrifuged at $1500 \times \mathrm{g}$ for $5 \mathrm{~min}$ at $4^{\circ} \mathrm{C}$, as previously reported [19]. The post-nuclear lysate was placed on a sucrose gradient and centrifuged at $170,000 \times \mathrm{g}$ for $22 \mathrm{~h}$ at $4^{\circ} \mathrm{C}$ using a Beckman SW50 rotor. Fractions were then collected from the top of the gradient as follows: $0.5 \mathrm{ml}$ for fraction $1,0.25$ $\mathrm{ml}$ for fractions 2 to 11 , and $1 \mathrm{ml}$ for fractions 12 and 13 , while the pellet was dissolved in $0.08 \mathrm{ml}$ TNE buffer (fraction 14). A representative amount of each fraction was subjected to flotillin-1 immunoblot analysis by $12 \%(\mathrm{w} / \mathrm{v})$ SDS/PAGE, which was subsequently blotted onto a PVDF membrane and incubated with 1:500 diluted mouse monoclonal antibodies (BD Biosciences, San Diego, CA) and antimouse antibodies. Flotillin-1-positive fractions (from 3 to 5) were pooled as DRMs and extensively dialyzed against TNE buffer. $50 \mu \mathrm{l}$ aliquots of purified DRMs were deposited on freshly cut mica, incubated for $1 \mathrm{~h}$ and then rinsed with Milli-Q water for contact mode AFM analysis. AFM measurements were performed using a Dimension 3100 scanning probe microscope (Digital Instruments, Veeco, Santa Barbara, CA) equipped with a Nanoscope IIIa controller and a "G" scanning head (maximum scan size $100 \times 100 \mu \mathrm{m}$ ). Images were acquired in contact mode in liquid by using $\mathrm{V}$ shaped, non-conductive silicon nitride cantilevers (type DNP, Veeco; $115 \mu \mathrm{m}$ length, nominal spring constant 0.58 $\mathrm{N} / \mathrm{m}$ ) with pyramidal tips (nominal curvature radius in the $20-60 \mathrm{~nm}$ range) and a scan rate in the $0.5-2.0 \mathrm{~Hz}$ range. The minimum force used in contact mode imaging was $0.3 \mathrm{nN}$. Possible A $\beta 42$ oligomer-induced changes in raft morphology were investigated in samples prepared as described above, which were then incubated for $30 \mathrm{~min}$ in the presence of 1.0 $\mu \mathrm{M}$ oligomers, rinsed with Milli-Q and imaged in liquid. Fluorescence anisotropy (r) of 1,6-diphenyl-1,3,5-hexatriene (DPH, Sigma) was used to measure the structural order of the hydrophobic region of purified lipid rafts under steadystate conditions, using a Perkin-Elmer LS 55 luminescence spectrometer as previously reported [19]. Lipid rafts were incubated with $1.0 \mu \mathrm{M} \mathrm{A} \beta 42$ oligomers for $0,5,10,30$ and $60 \mathrm{~min}$ and then incubated for $30 \mathrm{~min}$ with $\mathrm{DPH}$ in a 1:250 probe-to-lipid ratio.

\section{Lipid Peroxidation Analysis}

Levels of $8-\mathrm{OH}$ isoprostanes were measured in cell lysates and DRMs, at $405 \mathrm{~nm}$, using the 8-isoprostane EIA kit (Cayman Chemical Company, Ann Arbor, MI), as previously reported [30]. Lipid peroxidation in rat neurons and human fibroblasts exposed to A $\beta 42$ oligomers was also analyzed using the fluorescent probe BODIPY 581/591 $\mathrm{C}_{11}$. Briefly, cells seeded on glass coverslips were pre-incubated for $20 \mathrm{~min}$ in the absence $(-)$ or presence $(+)$ of 1:100 diluted rabbit polyclonal anti-GM1 antibodies (Calbiochem; EMD Chemicals Inc., Darmstadt, Germany), or $4.5 \mu \mathrm{g} / \mathrm{ml}$ Alexa Fluor 647-conjugated cholera toxin subunit B (CTX-B, Molecular Probes), and then exposed to $A \beta 42$ oligomers for 30 min. Dye loading was achieved by adding 5.0 $\mu \mathrm{M}$ BODIPY (Molecular Probes), dissolved in $0.1 \%$ DMSO, to cell culture media for $30 \mathrm{~min}$ at $37^{\circ} \mathrm{C}$. Cells were fixed in $2 \%$ buffered 
paraformaldehyde for $10 \mathrm{~min}$ and levels of lipid peroxidation determined by simultaneous acquisition of green (ex $485 \mathrm{~nm} / \mathrm{em} 520 \mathrm{~nm}$ ) and red BODIPY fluorescence (ex $581 \mathrm{~nm} / \mathrm{em} 591 \mathrm{~nm}$ ), using a Leica TCS SP5 confocal scanning microscope (Mannheim, Germany) equipped with an argon laser source. A series of $1.0 \mu$ m-thick optical section's (1024 x 1024 pixels) were taken through the cell depth (at intervals of $0.5 \mu \mathrm{m}$ ), using a Leica Plan Apo $63 \mathrm{x}$ oil immersion objective, and then projected as a single composite image by superimposition.

\section{GM1 Modulation}

In fibroblasts, an increase in membrane GM1 content was achieved by adding $32 \mu \mathrm{M}$ bovine brain-derived GM1 (Sigma) to cell culture media for $48 \mathrm{~h}$, while neurons were treated with $100 \mu \mathrm{M}$ GM1 for $24 \mathrm{~h}$. GM1 depletion was achieved by inhibiting cell glucosylceramide synthase with $25 \mu \mathrm{M}$ D-threo-1-phenyl-2-decanoylamino-3-morpholino-1propanol (PDMP; Matreya, LLC, PA, USA) for $48 \mathrm{~h}$ in fibroblasts or for $24 \mathrm{~h}$ in neurons. Hydrolysis of the sialic acid moiety from gangliosides was achieved by exposing cells to an NAA cocktail $(117 \mathrm{mU} / \mathrm{ml}$ of $V$. cholerae NAA and 33 $\mathrm{mU} / \mathrm{ml}$ of $A$. ureafaciens NAA, Sigma) for $1.0 \mathrm{~h}$ at $37^{\circ} \mathrm{C}$ [31]. Membrane GM1 distribution in cells, seeded on glass coverslips, was monitored using 1:100 diluted rabbit polyclonal anti-GM1 antibodies and 1:1000 diluted Alexa Fluor 488-conjugated anti-rabbit antibodies. The emitted fluorescence was detected following excitation at $488 \mathrm{~nm}$ using a confocal scanning microscope. To quantify the fluorescence intensity of $A b_{G M 1}$, varying numbers of cells (10 to 22) were analyzed in each experiment using ImageJ (NIH, Bethesda, MD, USA). Fluorescent signals were expressed as fractional changes above the baseline, $\Delta F / F$, where $\mathrm{F}$ (assumed to be $100 \%$ ) is the average baseline fluorescence in control cells and $\Delta F$ represents fluorescence relative to baseline levels.

\section{A $\beta 42$ Binding to Lipid Rafts}

The colocalization of $A \beta 42$ oligomers with lipid raft gangliosides was analyzed in fibroblasts seeded on glass coverslips, using monoclonal mouse $6 \mathrm{E} 10$ anti-A $\beta$ antibodies (Signet, Dedham, MA) and Alexa Fluor 647-conjugated CTX-B as previously reported [19], and evaluated by confocal scanning microscopy. GM1-A $\beta 42$ aggregate colocalization at the cell surface was estimated in regions of interest (10-12 cells) using ImageJ (NIH, Bethesda, MD, USA) and JACOP plug-in (rsb.info.nih.gov) software [32].

\section{Confocal Microscope Analysis of Cytosolic $\mathrm{Ca}^{2+}$ Dysregu- lation and Membrane Permeability}

Modulation of GM1 content or structure in rat neurons and human fibroblasts was followed by exposure to $A \beta 42$ oligomers for $30 \mathrm{~min}$ at $37^{\circ} \mathrm{C}$. Cells were treated with 8.8 $\mu \mathrm{M}$ fluo3-AM (in a 1:1 ratio with pluronic acid F-127 $(0.01 \% \mathrm{w} / \mathrm{v})$, Molecular Probes) resuspended in Hank's balanced saline solution (HBSS), for $30 \mathrm{~min}$ at $37^{\circ} \mathrm{C}$ and then fixed in $2 \%$ buffered paraformaldehyde for $10 \mathrm{~min}$ at room temperature. The emitted fluorescence was detected after excitation at $488 \mathrm{~nm}$ using the confocal scanning system. To quantify fluo 3 fluorescence, varying numbers of cells (10 to 22 ) in each experiment were analyzed using Image J $\mathrm{NIH}$,
Bethesda, MD, USA). Fluorescent signals were expressed as fractional changes above the baseline, $\Delta F / F$, where $\mathrm{F}$ (assumed to be $100 \%$ ) represents the fluorescence emitted by A 342 -exposed control cells with basal GM1 content and $\Delta F$ represents fluorescence relative to baseline levels. Fibroblasts seeded on glass coverslips, whose GM1 content or structure had previously been modulated, were loaded with $2.0 \mu \mathrm{M}$ calcein-AM (Molecular Probes) for $20 \mathrm{~min}$ at $37^{\circ} \mathrm{C}$. The fluorescence decay was analyzed after cell exposure to $1.0 \mu \mathrm{M} \mathrm{A} \beta 42$ aggregates for 0 and $30 \mathrm{~min}$ at $37^{\circ} \mathrm{C}$. Emitted fluorescence was detected after excitation at $488 \mathrm{~nm}$ using the confocal scanning system.

\section{Cytotoxicity Assay}

Aggregate cytotoxicity was assessed in rat neurons and human fibroblasts seeded in 96-well plates using the 3-(4,5dimethylthiazol-2-yl)-2,5-diphenyltetrazolium bromide (MTT) assay. Cells whose GM1 content or structure had previously been modulated were exposed to $1.0 \mu \mathrm{M}$ (fibroblasts) or $5.0 \mu \mathrm{M}$ (neurons) A 342 aggregates for $24 \mathrm{~h}$, subsequently incubated with a $0.5 \mathrm{mg} / \mathrm{ml}$ MTT solution for $4 \mathrm{~h}$ at $37^{\circ} \mathrm{C}$ and with cell lysis buffer $(20 \% \mathrm{SDS}, 50 \% \mathrm{~N}, \mathrm{~N}-$ dimethylformamide, $\mathrm{pH} 4.7$ ) for $3 \mathrm{~h}$. Absorbance values of blue formazan were determined at $590 \mathrm{~nm}$. Cell viability was expressed as a percentage of MTT reduction in treated cells compared to corresponding untreated cells.

\section{Statistical Analysis}

All data was expressed as mean \pm standard deviation (SD). Comparisons between different groups were performed using ANOVA followed by the Bonferroni t-test. A $p$-value less than 0.05 was accepted as statistically significant.

\section{RESULTS}

Lipid Rafts are Primary Interaction Sites for $A \beta 42$ in FAD Fibroblasts Secreting Enhanced $A \beta 42$ Levels

Mutations in presenilin (PS-1 and PS-2) or amyloid precursor protein (APP) genes have been shown to increase production of $A \beta 42$, i.e. the most amyloidogenic form of $A \beta$ [7]. Accordingly, higher levels of A $\beta 42$ were found in the culture media of PS-1Leu392Val, PS-1Met146Leu and APPVal717Ile fibroblasts from FAD patients, compared to WT fibroblasts from healthy subjects (Fig. 1A left). APP fibroblasts, in particular, released significantly more $\mathrm{A} \beta 42$ than PS- 1 cells. No significant difference in A $\beta 42$ production was observed in PS-1 fibroblasts bearing Leu392Val or Met146Leu mutations (data not shown). We previously found elevated amounts of $A \beta 42$ peptide in neuroblastoma cells overexpressing APPwt and APPV717G and in their culture media as compared to control cells, which results in greater lipid peroxidation $A \beta 42$ aggregate recruitment to the plasma membrane [22]. We therefore investigated whether FAD fibroblasts with altered APP processing display increased oxidative damage. $8-\mathrm{OH}$ isoprostane levels were significantly higher in PS-1 and APP fibroblasts with respect to WT fibroblasts (Fig. 1A right). Confocal microscope analysis confirmed the presence of enhanced cell-surface oxidation in FAD fibroblasts displaying greater basal $A \beta$ production, as assessed using the fluorescent probe BODIPY $581 / 591 C_{11}$ (Fig. 1B). Moreover, the increase in lipid pero- 
A
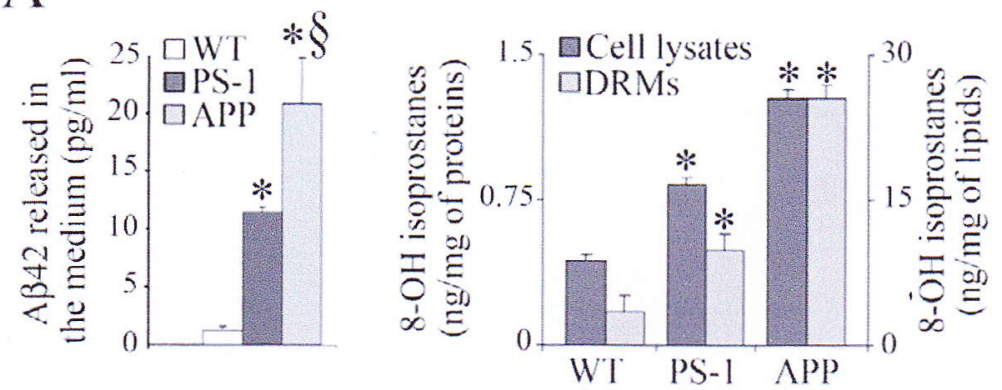

B
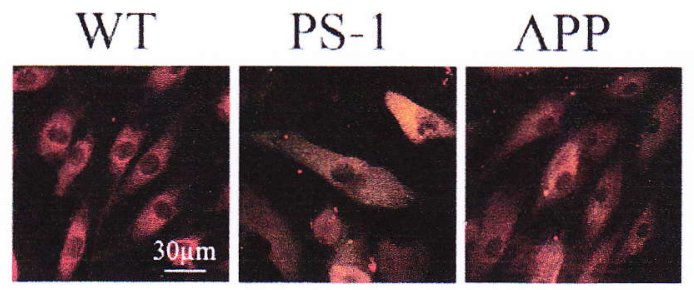

Fig. (1). Lipid rafts mediate A $\beta 42$-induced lipid peroxidation. (A) Left, A 342 levels in the cell culture media of WT, PS-1 and APP fibroblasts were measured using a commercial ELISA kit. Left, 8-OH isoprostane levels were quantified both in cell lysates and in pooled flotillin1-positive fractions (DRMs) purified from WT, PS-1 and APP fibroblasts. The reported values (means \pm S.D.) are representative of three independent experiments carried out in triplicate. The symbols * and $\S$ indicate significant differences relative to WT or PS-1 samples, respectively ( $\mathrm{p} \leq 0.05$ ). (B) Representative confocal microscope images of lipid peroxidation in WT, PS-1 and APP fibroblasts were obtained using the fluorescent probe BODIPY 581/591C 11 .

xidation was higher in DRMs (Fig. 2A left) compared to the entire membrane component (Fig. 1B), pointing to lipid rafts as a preferential site for $A \beta 42$ interaction at the cell surface. Accordingly, greater $A \beta 42$-induced oxidative damage in FAD fibroblasts was associated with marked alteration of DRM morphology, as observed by contact mode AFM. In particular, steps/cavities (white arrows), which were absent from WT DRMs, were found in PS-1 and, to a greater extent, in APP samples (Fig. 2A right). Modification of the plasma membrane is evident from its granular appearance, where multiple small defects are formed. The increased membrane damage observed in APP samples correlates well with their increased release of A $\beta 42$, compared to PS-1 samples. Furthermore, exposure of DRMs purified from WT fibroblasts to $A \beta 42$ oligomers for 30 min generated several small lesions in lipid rafts (Fig. 2B right; white arrows). Accordingly, the fluorescence anisotropy constant (r) of 1,6diphenyl-1,3,5-hexatriene (DPH), which is inversely proportional to the degree of membrane fluidity, was higher in DRMs from PS-1 and APP fibroblasts than that in lipid rafts from WT fibroblasts (Fig. 2B left). Moreover, DRMs obtained from PS-1 and, to a greater extent, APP fibroblasts showed a greater increase in stiffness when exposed to $A \beta 42$ oligomers, with respect to rafts purified from WT fibroblasts. Similar effects were observed in DRMs extracted from SHSY5Y neuroblastoma cells overexpressing APP when AFM and DPH fluorescence analysis were performed [19, 22].

\section{GM1 Mediates A $\beta 42$ Accumulation and Cytotoxicity in FAD Fibroblasts}

Cholesterol and monosialoganglioside GM1 are two key components of lipid rafts, which are increasingly accepted as playing an important role in stimulating protein aggregation and forming interactions with protein oligomers $[21,23,25$, 31]. Here, we investigated the dependence of $A \beta 42$ oligomer-induced cytotoxicity on membrane GM1 content in FAD and WT fibroblasts. In particular, we modified membrane GM1 content by incubating FAD and healthy fibroblasts in the presence of either bovine brain GM1 or PDMP, a GM1 biosynthesis inhibitor. Morphological evaluation of FAD and healthy fibroblasts by confocal microscopy revealed clear modulation of membrane GM1 content under our experimental conditions (Fig. 3A). As shown in Fig. 3C, the increase in GM1 content triggered a slight increase in A $\beta 42$ toxicity compared to that observed in fibroblasts with basal GM1 content. Conversely, PDMP-induced GM1 depletion suppressed cell susceptibility to $A \beta 42$ oligomers (Fig. 3B). Moreover, cell treatment with anti-GM1 antibodies $\left(\mathrm{Ab}_{\mathrm{GM} 1}\right)$ or cholera toxin subunit-B (CTX-B) protected fibroblasts from $\mathrm{A} \beta 42$ oligomer-induced cytotoxicity. A similar trend was observed when cells were treated with neuraminidase (NAA), which removes the sialic acid moiety from GM1, suggesting a major role for raft GM1 - particularly its negatively charged head group - in amyloid-induced cytotoxicity (Fig. 3B). Accordingly, treatment with NAA reduced the number of $A \beta 42$ oligomer-GM1 interactions. We observed marked colocalization of $A \beta 42$ oligomers with gangliosides in fibroblast membranes following exposure to A 342 aggregates (Fig. 3C). In particular, where green and red fluorescent signals were merged, a number of yellow areas, representing A $\beta 42-G M 1$ colocalization, were evident in PS-1 and APP fibroblasts. Scatter plots of fluorescence signals, analyzed using Pearson's correlation coefficient and the overlap coefficient according to Manders, yielded about $65 \% \mathrm{~A} \beta 42-\mathrm{GM} 1$ colocalization in PS-1 and APP fibroblasts, and $50 \%$ in WT fibroblasts obtained from healthy subjects. Treatment with NAA led to fewer interactions between 
A 342 oligomers and GM1, resulting in about $20 \%$ colocalization in FAD fibroblasts and $15 \%$ colocalization in WT cells, compared to cells where GM1 charge was unaltered (Fig. 3C).

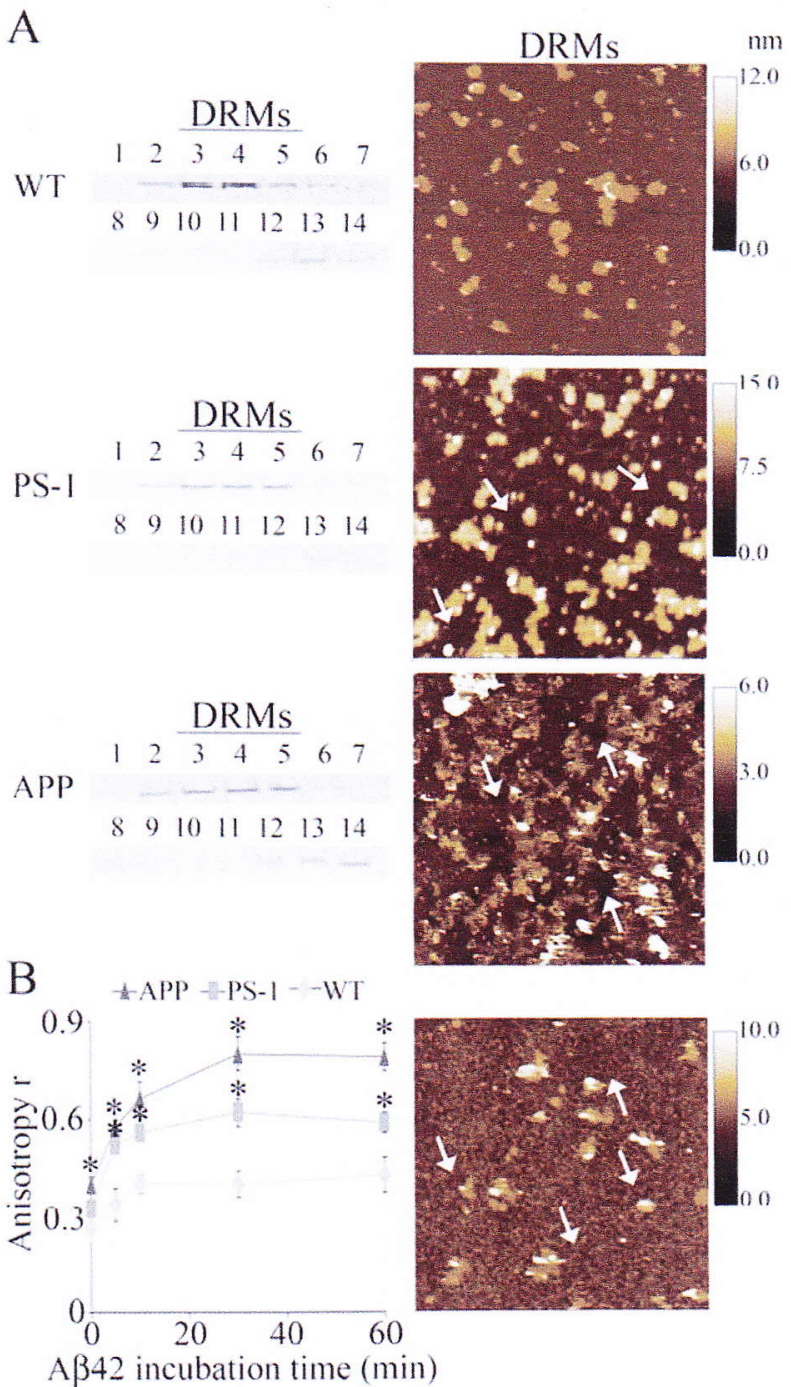

Fig. (2). A $442-G M 1$ interactions induce structural modification of DRMs. (A) Left panel, representative Western blot analysis of flotillin-1 levels in WT, PS-1 and APP fibroblasts, determined from 14 sucrose gradient fractions collected from the top (low density) to the bottom (high density) of the gradient tube. An aliquot from each fraction was run on $12 \%$ SDS/PAGE, transferred onto a PVDF membrane and then incubated with mouse monoclonal anti-flotillin1 antibodies. Right panel, AFM images of flotillin-1-positive fractions (DRMs) enriched in lipid raft microdomains (from 3 to 5), pooled and analyzed by contact mode AFM in liquid with a scan size of $5 \mu \mathrm{m}$. Representative images showed that steps or cavities were present in PS-1 and APP DRMs (white arrows). (B) DPH fluorescence anisotropy, $r$, measured by incubating rafts from WT, PS-1 and APP fibroblasts with $1.0 \mu \mathrm{M}$ A $\beta 42$ oligomers for $0,5,10$, 30 and $60 \mathrm{~min}$, and then with DPH for $30 \mathrm{~min}$. All data is mean \pm S.D. of four independent experiments, each performed in duplicate. ${ }^{*} p \leq 0.05$, significant difference $v s$ WT fibroblasts. Representative AFM image of DRMs purified from WT fibroblasts after $30 \mathrm{~min}$ incubation with $1.0 \mu \mathrm{M} \mathrm{A} \beta 42$ oligomers. Scan size $5 \mu \mathrm{m}$.
A
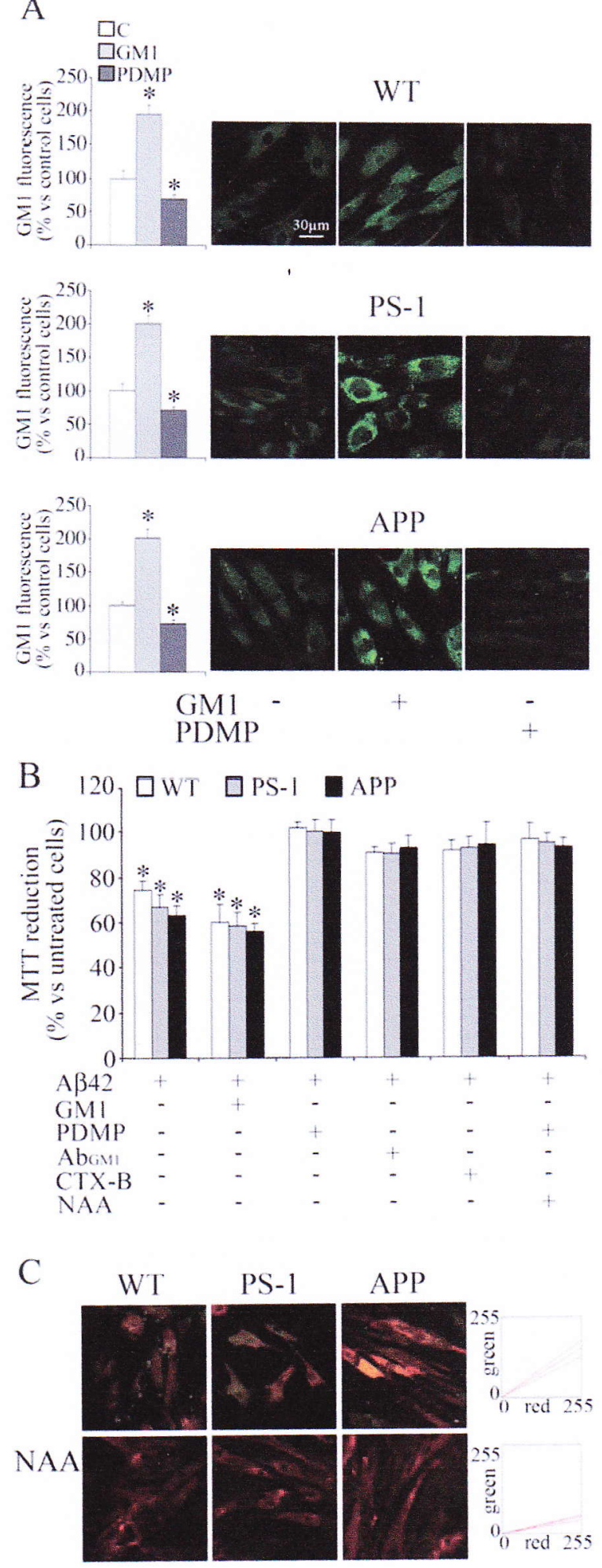

Fig. (3). Membrane GM1 modulates $A \beta 42$ accumulation at the plasma membrane and its cytotoxic effects. (A) Representative confocal microscope images of GM1 content in WT, PS-1 and APP fibroblasts under basal conditions, or following treatment with 32 $\mu \mathrm{M}$ GM1 or $25 \mu \mathrm{M}$ PDMP for $48 \mathrm{~h}$ at $37^{\circ} \mathrm{C}$. Semi-quantitative values of the green fluorescent signal (rabbit polyclonal anti-GM1 antibodies) are shown on the left of each image. The values shown are means \pm S.D. of three independent experiments, each carried 
out in triplicate. ${ }^{*} p \leq 0.05$, significant difference $v s$ relative control cells with basal GM1 levels. (B) Aggregate cytotoxicity in FAD and WT fibroblasts was assessed using the MTT assay. Cells were GM1-enriched (GM1), GM1-depleted (PDMP) or incubated in the absence or presence of $\mathrm{Ab}_{\mathrm{GM} 1}$, CTX-B or NAA, prior to treatment with $1.0 \mu \mathrm{M} \mathrm{A} \beta 42$ aggregates for $24 \mathrm{~h}$ at $37^{\circ} \mathrm{C}$. Cell viability was expressed as a percentage of MTT reduction in treated cells compared to corresponding untreated cells, where it was assumed to be $100 \%$. The reported values are means \pm S.D. of three independent experiments, each carried out in triplicate. ${ }^{*} p \leq 0.05$, significant difference $v s$ relative control cells. (C) Representative confocal microscope images showing A $\beta 42$ colocalization with GM1 (yellow) in WT, PS-1 and APP fibroblasts, under basal conditions (upper panel) or following treatment with NAA (lower panel). WT, PS-1 and APP fibroblasts were treated with $1.0 \mu \mathrm{M}$ A $\beta 42$ for 30 min and then labeled with mouse monoclonal $6 \mathrm{E} 10$ anti-A 42 and fluorescein-conjugated anti-mouse antibodies (green), while GM1 was stained with fluorescently-conjugated CTX-B (red). Scatter plots compare Aß42-GM1 colocalization in WT, PS-1 and APP fibroblasts under basal conditions. Pixels were plotted as a function of red ( $x$ axis) and green ( $y$ axis) fluorescence intensity, resulting in partial Aß42-GM1 colocalization.

\section{GM1 Mediates A $\beta$ 42-Induced $\mathrm{Ca}^{2+}$ Dyshomeostasis, Lipid Peroxidation and Cytotoxicity in Rat Cortical Neu- rons}

Perturbation of ion distribution across the plasma membrane is one of the earliest modifications displayed by cells exposed to toxic amyloid aggregates $[12,33,34]$. We therefore investigated the effects of $A \beta 42$ oligomers on intracellular $\mathrm{Ca}^{2+}$ content and membrane lipoperoxidation in cultured rat cortical neurons displaying varying GM1 content. A moderate increase in membrane GM1 content, as assessed by confocal microscopy using $\mathrm{Ab}_{\mathrm{GM} 1}$ antibodies (Fig. 4A), resulted in a sharper increase in cytosolic $\mathrm{Ca}^{2+}$ (Fig. 4B) and membrane oxidation (Fig. 4C) in neurons, compared to that observed in A 342 -exposed cells with basal GM1 content (Fig. 4B,C). In contrast, following PDMP-induced GM1 depletion the binding of $\mathrm{Ab}_{\mathrm{GM}}$ to raft monosialoganglioside and sialic acid hydrolysis by NAA precluded the increase in intracellular $\mathrm{Ca}^{2+}$ (Fig. 4B) and membrane lipoperoxidation (Fig. 4C). In particular, GM1 enrichment resulted in a significant increase (by $\sim 30 \%$ ) of the oligomer-induced cytosolic $\mathrm{Ca}^{2+}$ rise with respect to control A $\beta 42$-treated cells, whilst, GM1 depletion, $\mathrm{Ab}_{\mathrm{GM} 1}$ binding or sialic acid hydrolysis determined a smaller (by $\sim 45 \%$ ) rise in cytosolic $\mathrm{Ca}^{2+}$ with respect to control cells with basal GM1 content and exposed to $A \beta 42$ oligomers, as assessed by fluorescence intensity signals analyses. This suggests a specific role for lipid rafts, particularly GM1, in mediating $A \beta$-induced calcium dyshomeostasis. No change in cytosolic $\mathrm{Ca}^{2+}$ levels was observed when rat neurons, in the absence of A $\beta 42$ oligomers, were pre-treated so as to modulate GM1 content, exposure or charge. Moreover, membrane oxidation was prevented by culturing cells in a $\mathrm{Ca}^{2+}$-free medium, suggesting that the influx of extracellular $\mathrm{Ca}^{2+}$ is involved in $\mathrm{A} \beta 42$ oligomer-induced lipid peroxidation (Fig. 4C). Next, we investigated whether changes in cytosolic calcium levels and membrane lipoperoxidation also resulted in neurotoxicity. As shown in Fig. 4D, A $\beta 42$ oligomers caused a marked de- crease in MTT reduction compared to untreated cells. Moreover, an increase in GM1 content triggered a slight increase in $A \beta 42$ toxicity relative to that observed in neurons with basal GM1 content. In contrast, membrane GM1 depletion and GM1 charge modification improved neuronal viability, confirming the role of GM1 raft domains in amyloidinduced cytotoxicity.
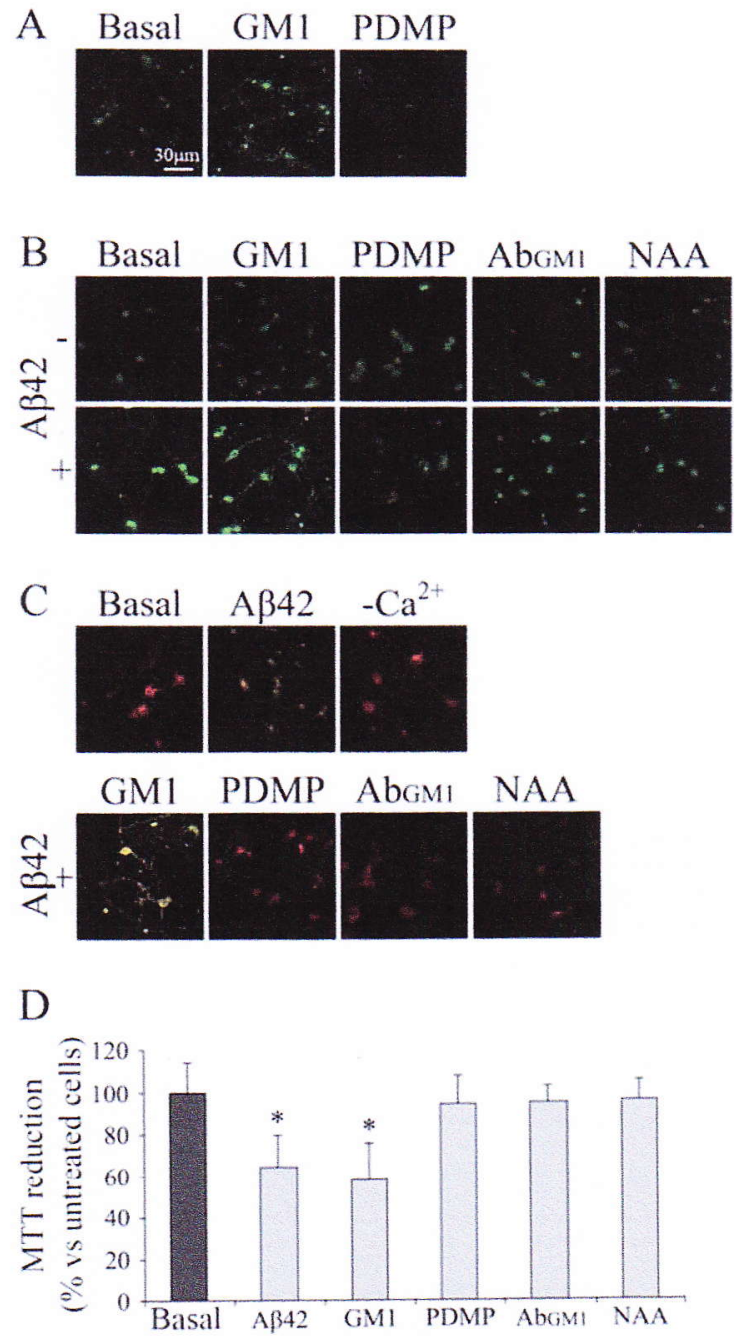

Fig. (4). GM1 depletion reduces A $\beta 42$-induced $\mathrm{Ca}^{2+}$ dyshomeostasis, membrane lipoperoxidation and cytotoxicity in rat cortical neurons. (A) Representative confocal microscope images of GM1 content in neurons under basal conditions, or following treatment with $100 \mu \mathrm{M}$ GM1 or $25 \mu \mathrm{M}$ PDMP for $24 \mathrm{~h}$ at $37^{\circ} \mathrm{C}$. (B) Representative confocal microscope images of cytosolic $\mathrm{Ca}^{2+}$ levels in neurons, under basal conditions or following treatment with GM1, PDMP, $\mathrm{Ab}_{\mathrm{GM} 1}$ or NAA, exposed to $5.0 \mu \mathrm{M}$ A 342 aggregates for 0 $(-)$ or $30(+)$ min at $37^{\circ} \mathrm{C}$. Cells were then treated for $30 \mathrm{~min}$ with $8.8 \mu \mathrm{M}$ fluo-3-AM. (C) Representative confocal microscope images of lipid peroxidation in cells under basal conditions or preincubated with GM1, PDMP; $\mathrm{Ab}_{\mathrm{GM} 1}$ or NAA, and subsequently exposed to $5.0 \mu \mathrm{M}$ A $\beta 42$ oligomers $(+)$ for $30 \mathrm{~min}$. As a control, cells were also exposed to A $\beta 42$ aggregates in a $\mathrm{Ca}^{2+}$-free medium. Lipid peroxidation was analyzed using the fluorescent probe BODIPY $581 / 591 \mathrm{C}_{11}$. (D) MTT reduction assay carried out in cells pre-treated with GM1, PDMP, $\mathrm{Ab}_{\mathrm{GM} 1}$ or NAA, prior to treatment with $5.0 \mu \mathrm{M}$ A $\beta 42$ aggregates for $24 \mathrm{~h}$ at $37^{\circ} \mathrm{C}$. Cell viability was 
expressed as a percentage of MTT reduction in treated cells compared to corresponding untreated cells, where it was assumed to be $100 \%$. The reported values are means \pm S.D. of three independent experiments, each carried out in triplicate. ${ }^{*} p \leq 0.05$, significant difference $v s$ relative control cells.

\section{GM1 Mediates A $\beta$ 42-Induced $\mathrm{Ca}^{2+}$ Dyshomeostasis, Lipid Peroxidation and Membrane Permeabilization in FAD Fibroblasts}

Consistent with our findings in rat neurons, a sharp increase in cytosolic $\mathrm{Ca}^{2+}$ was observed in FAD and WT fibroblasts exposed to $\mathrm{A} \beta 42$ oligomers (Fig. 5A). In particular, the increase in intracellular $\mathrm{Ca}^{2+}$ levels in PS-1 and APP fibroblasts was greater than that observed in WT cells. Furthermore, GM1 enrichment triggered a greater increase (by $60 \%$ ) in cytosolic $\mathrm{Ca}^{2+}$ levels upon oligomer exposure relative to basal cells, while no change in $\mathrm{Ca}^{2+}$ levels was observed when fibroblasts were treated with GM1 (or PDMP) in the absence of A $\beta 42$ oligomers (Fig. 5B). In contrast, a decrease in membrane GM1, following cell treatment with PDMP (Fig. 3A), resulted in reduced (by 50\%) A $\beta 42$ oligomer-induced $\mathrm{Ca}^{2+}$ spikes (Fig. 5A) with respect to basal cells; similar results were observed following cell treatment with $\mathrm{Ab}_{\mathrm{GM} 1}$, CTX-B or NAA prior to $\mathrm{A} \beta 42$ exposure. Accordingly, GM1 binding with $\mathrm{Ab}_{\mathrm{GM} 1}$ and CTX-B prevented the sharp increase in membrane oxidation (Fig. 5C). Moreover, BODIPY-loaded FAD fibroblasts showed a greater shift to green fluorescence than WT cells when exposed to $A \beta 42$ aggregates. However, this fluorescence shift was precluded by culturing cells in a $\mathrm{Ca}^{2+}$-free medium, confirming that the influx of extracellular $\mathrm{Ca}^{2+}$ is involved in the lipid peroxidation process induced by $\mathrm{A} \beta 42$ oligomers. Accordingly, the presence of $A \beta 42$ aggregates in the cell culture medium triggered a sharp decrease in calcein fluorescence, indicating that A $\beta 42$ oligomers trigger loss of membrane integrity and membrane permeabilization in fibroblasts (Fig. 6). Greater calcein leakage was observed in APP and PS-1 fibroblasts compared to WT controls, suggesting extensive A $\beta 42$ aggregate-induced membrane permeabilization in the former. Indeed, calcein-loaded APP and PS-1 fibroblasts fluoresced less than WT fibroblasts even prior to exogenous addition of A 342 aggregates (Fig. 6), perhaps reflecting greater amyloid-induced membrane damage in FAD cells, which display enhanced $A \beta$ production (Fig. 1A). No decrease in calcein fluorescence was observed in $\mathrm{A} \beta 42$ oligomer-exposed, GM1-depleted fibroblasts. In contrast, in GM1-enriched fibroblasts, marked calcein leakage was observed upon exposure to $A \beta 42$ oligomers. Accordingly, the binding of $A b_{G M 1}$ and CTX-B to raft GM1 attenuated A 342 -induced membrane permeabilization (as shown by decreased calcein leakage), as did treatment with NAA.

\section{DISCUSSION}

AD pathogenesis, with regards PS and APP mutations, has been attributed to toxic effects associated with the overproduction and aggregation of $A \beta$ peptides, particularly the more hydrophobic A $\beta 42$ [7]. This hypothesis was originally based on the premise that pathogenic mutations increase $\mathrm{A} \beta 42$ production by favoring proteolytic processing of APP by $\beta$ - or $\gamma$-secretase, and by heightening the self-aggregation of $A \beta$ into amyloid fibrils $[35,36]$. In this study, fibroblasts from FAD patients carrying APPVal717Ile, PS-1Leu392Val or Met146Leu gene mutations secreted elevated amounts of A 342 and displayed greater membrane permeabilization and lipid peroxidation compared to WT fibroblasts from healthy subjects, suggesting partial disruption of membrane integrity and chronic oxidative stress associated with enhanced $A \beta$ production. These findings are in agreement with several other studies, which also show that lipid peroxidation is associated with $A \beta$ deposits in APP/PS-1-mutant AD brains and mice $[16,37]$. Oxidative damage may further increase $\mathrm{A} \beta$ binding to the cell surface: indeed, $\mathrm{A} \beta$ is reported to accumulate faster in membranes containing oxidatively damaged phospholipids than in membranes containing only unoxidized or saturated phospholipids [15]. Our results also showed that lipoperoxidation levels were higher in detergentresistant membranes (DRMs) compared to the entire plasma membrane, pointing to lipid rafts as preferential sites for $\mathrm{A} \beta 42$ interaction at the cell surface. Indeed, as observed by contact mode AFM, the increased release of $A \beta 42$ in FAD fibroblasts was associated with marked alteration of lipid raft morphology, resulting in the formation of steps/cavities in PS-1 and, to a greater extent, in APP DRMs. Our observations are in agreement with AFM data obtained in reconstituted planar lipid bilayers, in which $A \beta 42$ treatment resulted in the formation of multimeric channel-like structures [38]. Conversely, other AFM studies have shown that the amyloidogenic peptide amylin induces small defects across the whole lipid surface and trigger lipid loss, rather than formation of discrete protein pores [39]. We also found that $A \beta$ treatment promoted greater aggregate-ganglioside colocalization and alteration of DRM structure in FAD fibroblasts compared to WT controls. Our approach allowed us to study the role of lipid rafts in $A \beta$-induced cytotoxicity in cells displaying genetic defects. Indeed, FAD-mutant fibroblasts displayed enhanced raft damage, suggesting that modified molecular structure is a common feature of cells displaying these genetic mutations. This evidence strengthens the claim that lipid rafts are important plasma membrane targets for $A \beta 42$ oligomers. In agreement with our observations, $A \beta$ has been shown to be highly concentrated in lipid rafts in the brains of $\mathrm{Tg} 2576$ transgenic mice [40]. Aging and ApoE4 expression cooperatively accelerate $A \beta$ aggregation in the brain by increasing GM1 levels in neuronal membranes [41]. Moreover, an increase in GM1 was found in cell membranes purified from $\mathrm{AD}$ patients, relative to healthy controls [42]. In addition, an age-dependent local increase in ganglioside density and loss of cholesterol has been reported, with highdensity GM1 clustering at presynaptic neuritic terminals shown to be a critical step for $\mathrm{A} \beta$ deposition in $\mathrm{AD}[27,43]$ and for the subsequent increase in membrane lateral pressure [44]. Our study shows that GM1 plays a key role in determining the susceptibility of FAD fibroblasts to A $\beta 42$, modulating the binding of amyloid oligomers to lipid rafts and the toxic effects they induce. However, we cannot rule out the possibility that membrane GM1 clustering is involved in this process. Indeed, it has been reported that GM1 clusters, detected in synaptosomes prepared from aged mouse brains by the specific binding of $\mathrm{p} 3$ peptide, are necessary for ganglioside-bound $A \beta$ complex generation, which acts as a seed for $A \beta$ assembly in AD brain [27]. In addition, it has been demonstrated that alterations in membrane lipid composition, 
A

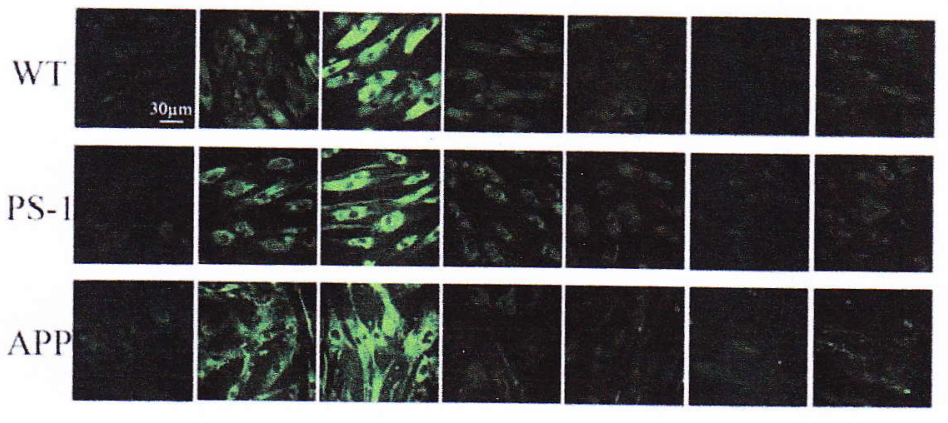

\begin{tabular}{|c|c|c|c|c|c|c|}
\hline$A \beta 42$ & + & + & + & + & + & + \\
\hline GMl & - & + & - & - & - & - \\
\hline PDMP & - & - & + & - & - & - \\
\hline$A b$ GMl & - & - & - & + & - & - \\
\hline CTX-B - & - & - & - & - & + & - \\
\hline NAA & - & - & - & - & - & + \\
\hline
\end{tabular}

B

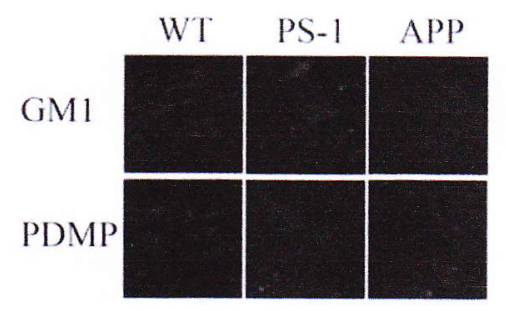

C

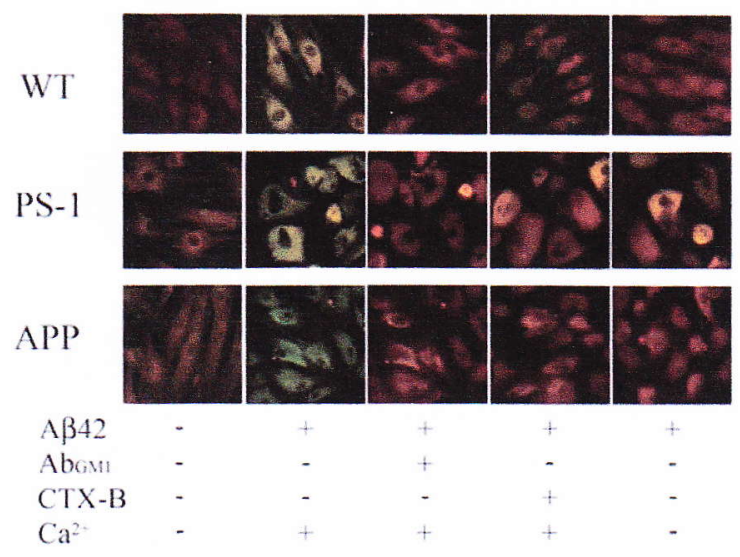

Fig. (5). GM1 depletion reduces A $\beta 42$-induced $\mathrm{Ca}^{2+}$ dyshomeostasis in FAD fibroblasts. Representative confocal microscope images of cytosolic $\mathrm{Ca}^{2+}$ levels in untreated or $1.0 \mu \mathrm{M}$ A $\beta 42$-exposed WT, PS-1 and APP fibroblasts, (A) under basal conditions or following treatment with GM1, PDMP, Ab $\mathrm{GM}_{\mathrm{GM}}$, CTX-B or NAA. (B) Cells were also enriched with GM1 or PDMP in the absence of A 342 oligomers. Cells were then treated for 30 min with $8.8 \mu \mathrm{M}$ fluo-3-AM. (C) Representative confocal microscope images of lipid peroxidation in untreated fibroblasts or fibroblasts pre-incubated for 20 min with $\mathrm{Ab}_{\mathrm{GM} 1}$ or $\mathrm{CTX}-\mathrm{B}$, and subsequently exposed to $1.0 \mu \mathrm{M} \mathrm{A} \beta 42$ oligomers for 30 min. As a control, cells were also exposed to $\mathrm{A} \beta 42$ aggregates in a $\mathrm{Ca}^{2+}$-free medium. Lipid peroxidation was analyzed using the fluorescent probe BODIPY $581 / 591 \mathrm{C}_{11}$.

including cholesterol enrichment and sphingomyelin depletion, enhanced high-density clustering of GM1 [26, 27]. We found that, even in rat cortical neurons, membrane GM1 content influences A $\beta 42$ toxicity and intracellular $\mathrm{Ca}^{2+}$ homeostasis, corroborating our hypothesis at the neuronal level. In particular, cell treatment with NAA, an enzyme that leaves the content and structure of GM1 unchanged except for the removal of the negatively charged sialic acid moiety, almost completely precluded A $\beta 42$ binding to the cell surface. In agreement with our observations, pre-treatment of neurons with either anti-GM1 antibodies or NAA has been shown to prevent $\mathrm{Ca}^{2+}$ spikes and protect against salmon calcitonin oligomer-induced neurotoxicity, likely modifying the plasma membrane region that is susceptible to the formation of pore-like structures [31]. On the other hand, GM1 has been shown to protect against A $\beta 25-35$ toxicity in hippocampal slices [45]. We also found a sharp increase in cytosolic $\mathrm{Ca}^{2+}$ levels and extensive alteration of membrane permeability in FAD and WT fibroblasts exposed to A $\beta 42$ oligomers. The increase in cytosolic $\mathrm{Ca}^{2+}$ content was milder in 


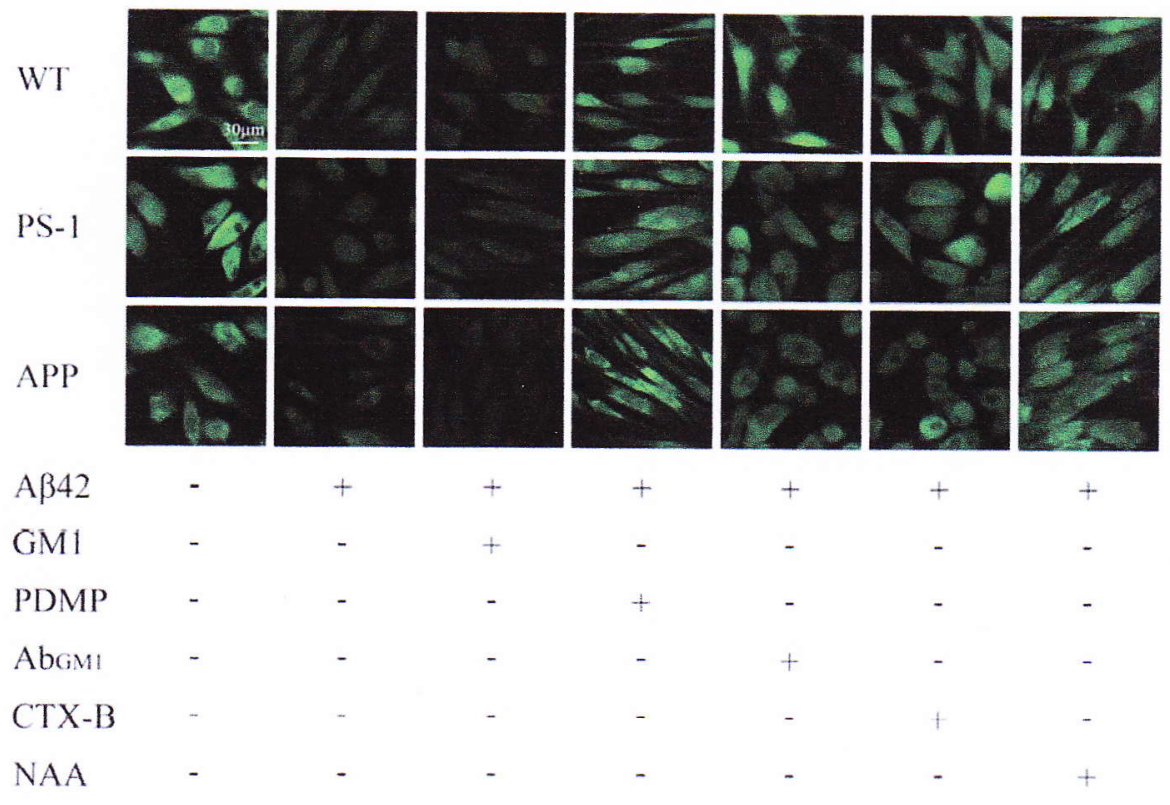

Fig. (6). GM1 depletion prevents A 342 oligomer-induced membrane permeabilization. Representative confocal microscope images showing

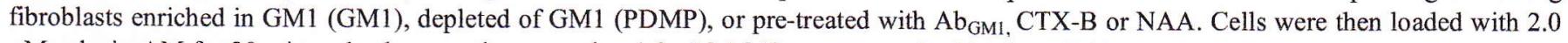
$\mu \mathrm{M}$ calcein-AM for $20 \mathrm{~min}$ and subsequently exposed to $1.0 \mu \mathrm{M} \mathrm{A} \beta 42$ aggregates for $30 \mathrm{~min}$ at $37^{\circ} \mathrm{C}$.

GM1-depleted fibroblasts exposed to amyloid oligomers than in similarly treated control cells with basal GM1 content. In contrast, GM1 enrichment triggered a greater increase in cytosolic $\mathrm{Ca}^{2+}$ levels and membrane permeabilization. Besides the physicochemical features of cell membranes, including fluidity, electrostatic potential, curvature and lateral pressure [46], the presence of specific membrane receptors, such as the receptor for advanced glycation end products (RAGE) [47] and several other cell surface proteins, including voltage- [48] and ligand-gated calcium channels [49], could in part explain the variable amyloidinduced intracellular calcium dyshomeostasis seen in neurons and fibroblasts. Moreover, pre-treatment of fibroblasts with anti-GM1 antibodies, cholera toxin subunit B - a specific GM1 ligand - or NAA completely suppressed A $\beta$ induced $\mathrm{Ca}^{2+}$ spikes and membrane damage, suggesting that the negative charge on GM1 is a key factor in determining calcium dyshomeostasis and membrane permeabilization. These effects could be due to oligomer-induced GM1 clustering, as reported for fibrils of the yeast prion Sup35p, which was shown to interact with lipid raft GM1, impairing its mobility at the membrane surface and triggering its clustering [50]. Our data also showed that A $\beta 42$-induced lipoperoxidation is inhibited by depletion of extracellular calcium, suggesting that oligomer-induced membrane oxidation is supported by $\mathrm{Ca}^{2+}$ uptake, which ultimately disrupts calcium homeostasis and activates signaling cascades that lead to cellular degeneration. The idea that calcium overload might be the final toxic insult to brain neurons in AD fits with numerous observations. The three major mechanisms of $A \beta$ interaction with cell membranes that have been proposed involve binding to endogenous calcium-permeable channels, disruption of membrane lipid integrity and the formation of calcium-permeable channels by $\mathrm{A} \beta[12,33,34]$. Our findings suggest that oligomers first increase $\mathrm{Ca}^{2+}$ uptake, possibly via amyloid channel formation, resulting in membrane pore formation and/or generalized thinning of the phospholipid bilayer that eventually leads to non-specific alteration of membrane permeability. From this point of view, modulation of membrane charge by sialic acid hydrolysis may specifically influence the binding of A 342 oligomers, their insertion into the phospholipid bilayer and their ability to oxidize membrane lipids, triggering cell death. However, the possibility that intracellular calcium overload is in part due to the interaction of oligomers with endogenous calcium-permeable channels cannot be ruled out. Intracellular $\mathrm{Ca}^{2+}$ stores have also been implicated in $\mathrm{Ca}^{2+}$ dysregulation. When presenilins are mutated, their function in ER $\mathrm{Ca}^{2+}$ leak is disrupted, contributing to cytosolic $\mathrm{Ca}^{2+}$ dysregulation [51, 52]. Greater knowledge of neuronal calcium dysregulation is needed, as calcium signaling modulators are targets of potential AD therapeutics. In conclusion, our findings obtained in two important model of AD such as primary neurons exposed to $A \beta 42$ oligomers and FAD fibroblasts strongly suggest that the binding of A 342 oligomers to the plasma membrane and the resulting disruption of membrane permeability is mediated by lipid raft microdomains, in particular by GM1 exposure and charge. Indeed, FAD-mutant fibroblasts displayed enhanced raft damage, suggesting that modified molecular structure is a common feature of cells displaying these genetic mutations.

\section{CONFLICT OF INTEREST}

The author(s) confirm that this article content has no conflicts of interest.

\section{ACKNOWLEDGEMENTS}

We thank Francesca Tatini for technical advice and Alessandra Gliozzi for helpful discussions. This study was supported by grants from the Italian MIUR (PRIN project no. 
2008R25HBW_002 and 20083ERXWS_002), Fondazione Cassa di Risparmio di Pistoia e Pescia Fondazione CARIGE and Ministry of Health RFPS-2007-2-39.

\section{REFERENCES}

[1] Haass C, Selkoe DJ. Soluble protein oligomers in neurodegeneration: lessons from the Alzheimer's amyloid beta-peptide. Nat Rev Mol Cell Biol 8: 101-12 (2007).

[2] Evin G, Weidemann A. Biogenesis and metabolism of Alzheimer's disease Abeta amyloid peptides. Peptides 23: $1285-97$ (2002)

[3] Marks N, Berg MJ. Neurosecretases provide strategies to treat sporadic and familial Alzheimer disorders. Neurochem Int 52: 184215 (2008).

[4] Selkoe DJ, Schenk D. Alzheimer's disease: molecular understanding predicts amyloid-based therapeutics. Annu Rev Pharmacol Toxicol 43: 545-84 (2003).

[5] St George-Hyslop PH. Molecular genetics of Alzheimer's disease. Biol Psychiatry 47: 183-99 (2000).

[6] Bettens K, Sleegers K, Van Broeckhoven C. Current status on Alzheimer disease molecular genetics: from past, to present, to future. Hum Mol Genet 19(R1): R4-11 (2010).

[7] Hardy J, Selkoe DJ. The amyloid hypothesis of Alzheimer's disease: progress and problems on the road to therapeutics. Science 297: 353-6 (2002)

[8] Lambert MP, Barlow AK, Chromy BA, Edwards C, Freed R, Liosatos $\mathrm{M}$, et al. Diffusible, nonfibrillar ligands derived from Abeta1-42 are potent central nervous system neurotoxins. Proc Natl Acad Sci USA 95: 6448-53 (1998).

[9] Van Helmond Z, Miners JS, Kehoe PG, Love S. Oligomeric Abeta in Alzheimer's disease: relationship to plaque and tangle pathology, APOE genotype and cerebral amyloid angiopathy. Brain Pathol 2: 468-80 (2010)

[10] Klein WL. Abeta toxicity in Alzheimer's disease: globular oligomers (ADDLs) as new vaccine and drug targets. Neurochem Int 41: 345-52 (2002).

[11] Dahlgren KN, Manelli AM, Stine Jr WB, Baker LK, Krafft GA, $\mathrm{LaDu}$ MJ. Oligomeric and fibrillar species of amyloid-beta peptides differentially affect neuronal viability. J Biol Chem 277: 32046-53 (2002)

[12] Arispe N, Diaz JC, Simakova O. Abeta ion channels: Prospects for treating Alzheimer's disease with Abeta channel blockers. Biochim Biophys Acta 1768: 1952-65 (2007).

[13] Kayed R, Sokolov Y, Edmonds B, McIntire TM, Milton SC, Hall $\mathrm{JE}$, et al. Permeabilization of lipid bilayers is a common conformation-dependent activity of soluble amyloid oligomers in protein misfolding diseases. J Biol Chem 279: 46363-6 (2004).

[14] Minami SS, Hoe HS, Rebeck GW. Fyn kinase regulates the association between amyloid precursor protein and Dab1 by promoting their localization to detergent-resistant membranes. J Neurochem 118: 879-90 (2011).

[15] Murray IV, Liu L, Komatsu H, Uryu K, Xiao G, Lawson JA, et al. Membrane-mediated amyloidogenesis and the promotion of oxidative lipid damage by amyloid beta proteins. J Biol Chem 282: 9335-45 (2007).

[16] Varadarajan S, Yatin S, Aksenova M, Butterfield DA. Review: Alzheimer's amyloid beta-peptide-associated free radical oxidative stress and neurotoxicity. J Struct Biol 130: 184-208 (2000).

[17] Kusumi A, Suzuki K. Toward understanding the dynamics of membrane raft-based molecular interactions. Biochim Biophys Acta 1746: 234-251 (2005)

[18] Allen JA, Halverson-Tamboli RA, Rasenick MM. Lipid raft microdomains and neurotransmitter signalling. Nature Neurosci 8: $128-$ 40 (2007).

[19] Cecchi C, Nichino D, Zampagni M, Bernacchioni C, Evangelisti E, Pensalfini A, et al. A protective role for lipid raft cholesterol against amyloid-induced membrane damage in human neuroblastoma cells. Biochim Biophys Acta 1788: 2204-16 (2009).

[20] Chen TY, Liu PH, Ruan CT, Chiu L, Kung FL. The intracellular domain of amyloid precursor protein interacts with flotilin-1, a lipid raft protein. Biochem Biophys Res Commun 342: 266-72 (2006).

[21] Ehehalt R, Keller P, Haass C, Thiele C, Simons K. Amyloidogenic processing of the Alzheimer beta-amyloid precursor protein depends on lipid rafts. J Cell Biol 160: 113-23 (2003).
[22] Zampagni M, Evangelisti E, Cascella R, Liguri G, Becatti M, Pensalfini A, et al. Lipid rafts are primary mediators of amyloid oxidative attack on plasma membrane. J Mol Med 88: 597-608 (2010).

[23] Ariga T, McDonald MP, Yu RK. Role of ganglioside metabolism in the pathogenesis of Alzheimer's disease--a review. J Lipid Res 49: $1157-75$ (2008).

[24] Cordy JM, Hussain I, Dingwall C, Hooper NM, Turner AJ. Exclusively targeting beta-secretase to lipid rafts by GPI-anchor addition up-regulates beta-site processing of the amyloid precursor protein. Proc Natl Acad Sci USA 100: 11735-40 (2003).

[25] Matsuzaki K, Kato K, Yanagisawa K. Abeta polymerization through interaction with membrane gangliosides. Biochim Biophys Acta 1801: 868-77 (2010).

[26] Yanagisawa K. Pathological significance of ganglioside clusters in Alzheimer's disease. J Neurochem 116: 806-12 (2011).

[27] Yamamoto N, Matsubara T, Sato T, Yanagisawa K. Age-dependent high density clustering of GM1 ganglioside at presynaptic neuritic terminals promotes amyloid beta-protein fibrillogenesis. Biochim Biophys Acta 1778: 2717-26 (2008).

[28] American Psychiatric Association. Diagnostic and statistical manual of mental disorders, 4 th edn. Washington DC (1994)

[29] The Dementia Study Group of the Italian Neurological Society. Guidelines for the diagnosis of dementia and Alzheimer's disease. Ital J Neurol Sci 21: 87-194 (2000).

[30] Pensalfini A, Zampagni M, Liguri G, Becatti M, Evangelisti E, Fiorillo $\mathrm{C}$, et al. Membrane cholesterol enrichment prevents A $\beta$ induced oxidative stress in Alzheimer's fibroblasts. Neurobiol Aging 32: 210-22 (2011).

[31] Malchiodi-Albedi F, Contrusciere V, Raggi C, Fecchi K, Rainaldi $\mathrm{G}$, Paradisi $\mathrm{S}$, et al. Lipid raft disruption protects mature neurons against amyloid oligomer toxicity. Biochim Biophys Acta 1802: 406-15 (2010).

[32] Rasband WS. ImageJ. U. S. National Institutes of Health, Bethesda, Maryland. Available at: http://rsb.info.nih.gov/ij/ (1997-2008).

[33] Decker H, Jürgensen S, Adrover MF, Brito-Moreira J, Bomfim TR, Klein WL, et al. N-methyl-D-aspartate receptors are required for synaptic targeting of Alzheimer's toxic amyloid- $\beta$ peptide oligomers. J Neurochem 115: 1520-9 (2010)

[34] Demuro A, Parker I, Stutzmann GE. Calcium signaling and amyloid toxicity in Alzheimer disease. J Biol Chem 285: 12463-8 (2010).

[35] Selkoe DJ, Wolfe MS. Presenilin: running with scissors in the membrane. Cell 131: 215-21 (2007)

[36] Steiner H, Winkler E, Haass C. Chemical cross-linking provides a model of the gamma-secretase complex subunit architecture and evidence for close proximity of the C-terminal fragment of presenilin with APH-1. J Biol Chem 283: 34677-86 (2008).

[37] Abdul HM, Sultana R, St Clair DK, Markesbery WR, Butterfield DA. Oxidative damage in brain from human mutant APP/PS-1 double knock-in mice as a function of age. Free Radic Biol Med 45: 1420-5 (2008).

[38] Lin H, Bhatia R, Lal R. Amyloid beta protein forms ion channels: implications for Alzheimer's disease pathophysiology. FASEB J 15: 2433-44 (2001)

[39] Green JD, Kreplak L, Goldsbury C, Li Blatter X, Stolz M, Cooper $\mathrm{GS}$, et al. Atomic force microscopy reveals defects within mica supported lipid bilayers induced by the amyloidogenic human amylin peptide. J Mol Biol 342: 877-87 (2004).

[40] Kawarabayashi T, Shoji M, Younkin LH, Wen-Lang L, Dickson DW, Murakami T, et al. Dimeric amyloid beta protein rapidly accumulates in lipid rafts followed by apolipoprotein E and phosphorylated tau accumulation in the Tg2576 mouse model of Alzheimer's disease. J Neurosci 24: $3801-9$ (2004).

[41] Yamamoto N, Igbabvoa U, Shimada Y, Ohno-Iwashita Y, Kobayashi M, Wood WG, et al. Accelerated Abeta aggregation in the presence of GM1-ganglioside-accumulated synaptosomes of aged apoE4-knock-in mouse brain. FEBS Lett 569: 135-9 (2004).

[42] Molander-Melin M, Blennow K, Bogdanovic N, Dellheden B, Månsson JE, Fredman P. Structural membrane alterations in Alzheimer brains found to be associated with regional disease development; increased density of gangliosides GM1 and GM2 and loss of cholesterol in detergent-resistant membrane domains. J Neurochem 92: 171-82 (2005).

[43] Fujita A, Cheng J, Hirakawa M, Furukawa K, Kusunoki S, Fujimoto T. Gangliosides GM1 and GM3 in the living cell membrane 
form clusters susceptible to cholesterol depletion and chilling. Mol Biol Cell 18: 2112-22 (2007).

[44] Lin MS, Chen LY, Wang SS, Chang Y, Chen WY. Examining the levels of ganglioside and cholesterol in cell membrane on attenuation the toxicity of beta-amyloid peptide. Coll Surf B Biomem 65: 173-7 (2008).

[45] Kreutz F, Frozza RL, Breier AC, de Oliveira VA, Horn AP, Pettenuzzo LF, et al. Amyloid- $\beta$ induced toxicity involves ganglioside expression and is sensitive to GM1 neuroprotective action. Neurochem Int 59:648-55 (2011).

[46] Stefani M. Protein folding and misfolding on surfaces. Int J Mol Sci 9: 2515-42 (2008)

[47] Yan SD, Stern D, Kane MD, Kuo YM, Lampert HC, Roher AE. RAGE-Abeta interactions in the pathophysiology of Alzheimer's disease. Restor Neurol Neurosci 12: 167-73 (1998).

[48] Hou X, Parkington HC, Coleman HA, Mechler A, Martin LL, Aguilar MI, et al. Transthyretin oligomers induce calcium influx via voltage-gated calcium channels. J Neurochem 100: 446-57 (2007).

[49] Pellistri F, Bucciantini M, Relini A, Nosi D, Gliozzi A, Robello M, et al. Nonspecific interaction of prefibrillar amyloid aggregates with glutamatergic receptors results in $\mathrm{Ca}^{2+}$ increase in primary neuronal cells. J Biol Chem 283: 29950-60 (2008).

[50] Bucciantini M, Nosi D, Forzan M, Russo E, Calamai M, Pieri L, et $a l$. Toxic effects of amyloid fibrils on cell membranes: the importance of ganglioside GM1. FASEB J 26: 818-31 (2012).

[51] Tu H, Nelson O, Bezprozvanny A, Wang Z, Lee SF, Hao YH, et al. Presenilins form ER Ca2+ leak channels, a function disrupted by familial Alzheimer's disease-linked mutations. Cell 126: 981-93 (2006).

[52] Zhang H, Sun S, Herreman A, De Strooper B, Bezprozvanny I, Role of presenilins in neuronal calcium homeostasis. J Neurosci 30: 8566-8580 (2010). 